\title{
Gender Roles by the Sambal-Bolinao in Their Traditional Herbal Healing in Bolinao, Pangasinan, Northern Philippines
}

\section{I.A. De Vera}

Faculty of Natural Science Department, Pangasinan State University-Binmaley Campus, Pangasinan, Philippines

W.T. Fajardo

Faculty of Natural Science Department, Pangasinan State University-Lingayen Campus, Lingayen, Pangasinan, Philippines

\section{Abstract}

Transmission of ethnobotanical knowledge is needed for cultural preservation and biodiversity conservation. Nowadays, this is seriously threatened by globalization which is evident in tropical areas due to influence of Western culture leading to rapid change in indigenous individual and the community. Several factors were attributed and associated with the use of plants in the indigenous communities which includes biological, ecological and socio-cultural with the inclusion of techniques, practices, religion and age. Moreover, gender influences the ethnobotanical knowledge and the structure of local medical systems. The study aimed to assess the gender roles, sanitation practice, and lifestyle of Sambal-Bolinao in their traditional herbal healing. Specifically, it sought to determine the traditional herbal healers' profile, gender roles; and sanitation practice and lifestyle. Descriptive research technique was employed in gathering data. All traditional herbal healers in the municipality of Bolinao were interviewed using semistructured questionnaire. A total of 19 managtambal; 11 males and 8 females. The Sambal-Bolinao Roman Catholic believers appreciated the practice of traditional herbal healing. They extended their roles as plant gatherers, keepers of the plant parts gathered, washers of the plant parts prior to treatment, managers of the plant parts wastes and as plant conservationist either through plant propagation and personal campaign on plant conservation. Majority of women traditional herbal healers did not transmit their ethnobotanical knowledge to their children and relatives due to their multiple burden case and perceived economic difficulty for their children. Men traditional herbal healers were the one transmitting their ethnobotanical knowledge to their family members.

Keywords: Gender roles, managtambal, traditional healers 


\section{Introduction}

The World Health Organization recognized that $80 \%$ of people from developing countries rely mainly on traditional medicine for primary health care. Healing using medicinal herbs or plants has been part of the Filipino culture and a tradition by the Sambal-Bolinao in Bolinao, Pangasinan, Northern Philippines. Herbal healing is also called botanical or phytomedical healing using a plant's seeds, fruits, flowers, roots, leaves, barks, and other plant parts for medicinal purposes. Although modern health facilities and healing exist nowadays, herbal healing by the Sambal-Bolinao still prevail revealing the value of herbal medicine and the tradition of treating and preventing diseases.

The Sambal-Bolinao people origin were Austronesian inhabitants of the province of Zambales. The Sambals in the province of Pangasinan are found in the municipality of Bolinao and Anda. The Sambals of Bolinao still believe in superstitions, mysteries and herbal healing. The word Sambal was originally called sambali by Spanish and coined from the Malay word, sembah meaning "to worship". Today, herbal healing is predominantly practiced by the Sambal-Bolinao men and women. They are called managtambal in the spoken dialect, Sambal. The managtambal have unusual healing practices and roles in the pre-treatment, treatment and post treatment of diseases.

In the $12^{\text {th }}$ century, the province of Pangasinan was ruled by a warrior princess called Urduja. During those times, women were given importance. They held high positions like healers, priestesses and even handle leadership roles and fight as warriors. The healer was called Babaylan and usually performed by a woman. When an occasion arises that a man would take this role, he needs to dress up as a woman. Women were looked up to because of their wisdom and knowledge. When problems arise and there were no other means to fix it, the Babaylan is the one to be called and perform rituals and chants to drive away the spirits that caused turmoil.

Fojas (2012) described Miguel de Loarca, a conquistador that gave a graphic description of the supernatural beliefs and religious practices of ancient Filipinos in Relacion de las Yslas Filipinas, a treatise on the Philippine islands that was published in Arevalo, Spain in June 1582. The priestesses or Babaylan cure diseases with medicinal herbs. They have a remedy for every kind of poison using antidotal herbs. They were very superstitious people.

As Saldua (2012) mentioned that glorious years of the women were destroyed when the Spanish arrived during the $16^{\text {th }}$ century. They brought with them their own idea of what a woman is and where she is supposed to be placed in society. Women were turned into objects of suppression. Men and women's role especially in traditional herbal healing had been altered. This was furthered by the coming of Americans, Japanese, and technologies brought by globalization. Yet, the supernatural beliefs and practices in herbal healing of their ancestors still exert a major influence in the daily lives of modern Filipinos. This is evident in the Sambal-Bolinao folk, hence, this study was made. 


\section{Objectives}

Today, there are still remnants of the past though quite different from its origin. Traditional herbal healing still exist and performed by the native men and women of Sambal-Bolinao in Bolinao, Pangasinan, Northern Philippines.This study aimed to assess the gender roles, sanitation practice, and lifestyle of Sambal-Bolinao in their traditional herbal healing.

Specifically it sought to determine the traditional herbal healers':

1. general information or profile;

2. gender roles; and

3. sanitation practice and lifestyle

\section{Methodology}

\section{Study Area}

The study was conducted in eleven barangays of the municipality of Bolinao in the province of Pangsinan. These barangays were Arnedo, Binabalian, Cabuyao, Culang, Goyoden, Lucero, Pilar, Samang Norte, Sampaloc, Tara, and Victory. These barangays were found to have existing traditional herbal healers. Bolinao is one of the blooming and first class municipalities of the province of Pangasinan. Bolinao has thirty (30) barangays with a total area of $197.22 \mathrm{~km}^{2}$. Bolinao lies in the coordinates of $\underline{6^{\circ} 20^{\prime} \mathrm{N}}$ $\underline{119^{\circ} 53^{\prime} \mathrm{E} .}$

The study sites were selected based on the following criteria: presence of active traditional herbal healers, traditional herbal healers willing to be interviewed and sites were accessible and peaceful. Primary and secondary data gathering were gathered from March 2016 to January 2017.

Figure 1 shows the map of the municipality of Bolinao, province of Pangasinan relative to the position of nearby provinces such as Benguet, La Union, Zambales, Tarlac, Nueva Ecija and Nueva Viscaya. It could be seen that Zambales is near the town of Bolinao.

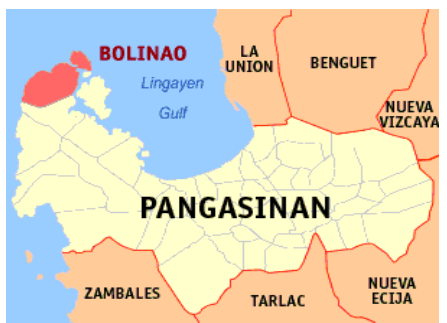

Figure 1. Map of the municipality of Bolinao, Pangasinan 


\section{Research Design}

This study focused on the gender roles, sanitation practice and lifestyle of SambalBolinao traditional herbal healers in Bolinao, Pangasinan, Northern Philippines. Descriptive research techniques was employed in gathering the needed data and information for the study. All traditional herbal healers existing in the municipality of Bolinao were interviewed using semi-structured questionnaire.

\section{Research Instrument and Data Collection Technique}

\section{Gathering of Secondary Data and Information}

Before the start of data collection, the researchers secured permission from the mayor of Bolinao, and local barangay officials. Also, endorsements from local Department of Interior and Local Government, Local Department of Health and Social Welfare were solicited.

\section{Data Collection}

The nineteen traditional herbal healers were individually interviewed using semistructured questionnaires. The respondents were purposively chosen based on the abovementioned criteria. The questionnaire was divided into 3 sections, namely: section 1, personal data or profile of the respondent; section 2, gender roles in drug preparation, its pre-treatment, treatment, post treatment, plant conservation, and transmission of traditional ethnobotanical knowledge; and section 3, sanitation practice and lifestyle of traditional herbal healers. Key informant interviews were done to seek advance information about the traditional herbal healing and the healers. Focused group was also employed to seek a view from different perspectives about the topic. This approach facilitated a sort of rapid appraisal assessment and allowed unanticipated data and information to emerge.

\section{Respondents}

The respondents of the study were the identified traditional herbal healers in Bolinao, Pangasinan, Northern Philippines. All the identified traditional herbal healers by the local government of Bolinao were interviewed. Hence, a total of 19 traditional herbal healer respondents including non Sambal blooded ones underwent in this study's survey. Replacement (usually by a family member) was considered when identified respondents were not available.

\section{Data Analyses}

In addition to information obtained from the interview questionnaires, information through observation and video/photo documentation were sought. Answers in every interview question were tabulated and calculated employing frequency distribution method. WPS Spreadsheet software program was used in encoding data and processing of information. Descriptive analysis was used for the interpretation of the data gathered. 


\section{Results and Discussions}

General Information about the Respondents

Table 1 shows the general information about the traditional herbal healers as respondents in the eleven barangays of Bolinao, Pangasinan, Northern Philippines. Results showed that barangay Victory had three female and one male traditional herbal healers. Barangay Culang had one female and two male traditional herbal healers. Barangays Arnedo, Binabalian, and Sampaloc had each one female and one male traditional herbal healers. Barangays Cabuyao, Goyoden, Lucero, Pilar, and Samang Norte, had one each male traditional herbal healer. Barangay Tara had one female traditional healer. All respondents were married and only one widowed female. Among the 8 female respondents, seven were Sambal blooded and only one female respondent was not. Among the eleven male traditional herbal healers, seven were Sambal blooded while four of them were not Sambals. Among eight female respondents, five were Roman Catholic believers, the three were non-Roman Catholic believers. Nine of the eleven male respondents were Roman Catholic believers and the two were non-Catholic believers.

Fojas(2012) described that most of the priestess or Babaylan were Roman Catholic believers. Roman Catholicism reinforced the pre-hispanic herbal healing practice. It could be inferred that most of the traditional herbal healers were Roman Catholic believers.

Table 1. General Information about the traditional healer respondents

\begin{tabular}{|c|c|c|c|c|c|c|c|c|c|c|c|c|c|c|}
\hline \multirow{3}{*}{$\begin{array}{l}\text { Name of the } \\
\text { barangay } \\
\text { where the } \\
\text { respondents } \\
\text { came }\end{array}$} & \multirow{2}{*}{\multicolumn{2}{|c|}{ Sex }} & \multicolumn{4}{|c|}{ Civil Status } & \multicolumn{4}{|c|}{ Ethnicity } & \multicolumn{4}{|c|}{ Religion } \\
\hline & & & \multicolumn{2}{|c|}{$\begin{array}{c}\text { Marrie } \\
\mathrm{d}\end{array}$} & \multicolumn{2}{|c|}{$\begin{array}{c}\text { Widowe } \\
\mathrm{d}\end{array}$} & \multicolumn{2}{|c|}{$\underset{\mid}{\text { Samba }}$} & \multicolumn{2}{|c|}{$\begin{array}{c}\text { Not } \\
\text { Sambal }\end{array}$} & \multicolumn{2}{|c|}{$\begin{array}{l}\text { Roman } \\
\text { Catholic }\end{array}$} & \multicolumn{2}{|c|}{$\begin{array}{c}\text { Other } \\
s\end{array}$} \\
\hline & $\begin{array}{c}\text { Femal } \\
\mathrm{e} \\
(\mathrm{F})\end{array}$ & $\begin{array}{c}\text { Mal } \\
\text { e } \\
\text { (M) }\end{array}$ & $\mathrm{F}$ & $\mathrm{M}$ & $\mathrm{F}$ & $M$ & $\mathrm{~F}$ & $M$ & $\mathrm{~F}$ & $M$ & $\mathrm{~F}$ & M & $\mathrm{F}$ & $M$ \\
\hline Arnedo & 1 & 1 & 1 & 1 & & & 1 & 1 & & & 1 & 1 & & \\
\hline Binabalian & 1 & 1 & 1 & 1 & & & 1 & 1 & & & 1 & 1 & 1 & \\
\hline Cabuyao & & 1 & & 1 & & & & 1 & & & & & & 1 \\
\hline Culang & 1 & 2 & 1 & 2 & & & 1 & 1 & & 1 & 1 & 2 & & \\
\hline Goyoden & & 1 & & 1 & & & & 1 & & & & & & 1 \\
\hline Lucero & & 1 & & 1 & & & & 1 & & & & 1 & & \\
\hline Pilar & & 1 & & 1 & & & & & & 1 & & 1 & & \\
\hline Samang Norte & & 1 & & 1 & & & & & & 1 & & 1 & & \\
\hline Sampaloc & 1 & 1 & 1 & 1 & & & 1 & & & 1 & 1 & 1 & & \\
\hline Tara & 1 & & 1 & & & & & & & & & & & \\
\hline Victory & 3 & 1 & 2 & 1 & 1 & & 3 & 1 & 1 & & 2 & 1 & 1 & \\
\hline Total & 8 & 11 & 7 & 11 & 1 & & 7 & 7 & 1 & 4 & 6 & 9 & 2 & 2 \\
\hline
\end{tabular}




\section{Gender Roles in Traditional Herbal Healing}

Shown in Table 2 is the gender roles in traditional herbal healing by the SambalBolinao. At least five gender roles were described by the traditional herbal healer respondents. Six out of eight female respondents did plant gathering as part of the healing preparation. The two female respondents depend either from family member or relative to gather the plant parts. Among the male respondents, seven did by themselves the plant gathering while four relied from their spouses and sometimes from their patients. In storing plant parts prior to pre-treatment and treatment, six of the female respondents did it themselves while the two depended from their family members. Washing the plant parts in the pre-treatment, and disposal of used or left over plant parts in the post treatment, six female respondents did by themselves and two female respondents asked their family members to do it. Three female respondents propagated by themselves the plants being used in healing as part of plant conservation. The other three female respondents requested or asked their family member to propagate the plants. Other conservation measure was to tell people to conserve the plant as done by two female respondents. Of all eight female respondents, only one was willing to transmit her ethnobotanical knowledge to her family members. Most of the reasons mentioned by the female respondents why they do not like to transmit their ethnobotanical knowledge was economic difficulty. Majority of these female respondents did not have regular source of income. Neither herbal healing was their means of income. On the transmission of ethnobotanical knowledge to their family members or relatives, only one female respondent was found out transmitting her knowledge to anyone of her family members. The rest of female respondents did not.

The male respondents, on the other hand, seven of them did gathering and storing of plant parts. The other four male respondents requested their patients or wives to gather and store the plants for them. In the pre-treatment or washing the plant parts, only one of the male respondents did not do it by himself. In the disposal of plant parts, seven male respondents did the disposal of the used or left over plant parts. The other four male respondents, sought their patients or wives to dispose the left over or used plant parts. In plant conservation, only one male respondent did the propagation of plant. The other male respondent requested a family member to do the propagation while three of male respondents did not mind the plant's propagation. Moreover, one male respondent did protect the plant wildlings and two male respondents did not bother to protect the plant wildlings. One male respondent told the people to conserve the plant used for healing. Two male respondents requested either their patients or family members to conserve the plant. Six out of eleven male respondents do not like to transmit their ethnobotanical knowledge. Like female respondents, their main reason was economic difficulty. Three of the male respondents primary occupation was carpentry, two were into fishing, the rest were senior citizens. Five out of eleven male respondents were already transmitting their 
ethnobotanical knowledge to their family members or relatives while six of them were not.

Sahibzada (2005) studied that the plant collectors or gatherers of medicinal plants in Roringar Valley, Swat, Pakistan include women (34\%), children (47\%), and men (19\%). Howard (2001) claimed that across the globe, and particularly in tropical regions rich in biodiversity, in villages, on farms, in homesteads, forests, common pastures, fields and borders, it is women who manage the majority of all plant resources that are used by humans. They also hold the majority of all local plant knowledge and are those who are mainly responsible for the in situ conservation and management of useful plants, whether they are domesticated or wild. The simple explanation for this is that, throughout history, women's daily work has required more of this knowledge. Across the globe, it is women who predominate as wild plant gatherers, homegardeners and plant domesticators, herbalists, and seed custodians. The study of Hunde et al (2015) concluded that Ethopian women were the major players in the conservation and managing medicinal plants. One of the gender biases being faced by Filipino women is multiple burden. They do all the household chores and extra living activities and almost have no time to mentor. These could be one of the reasons why female respondents did not transmit their ethnobotanical knowledge. Not wanting their children experience economic difficulty in the near future was one of the reasons for not transmitting their knowledge.

Both men and women traditional healers performed other roles like plant gatherer, keeper of left over plant parts, washer of the plant parts before treatment. They even disposed used plant parts in their post - treatment. All of the above roles were directly associated with their nature of work in herbal healing. In the conservation of plants being used for herbal healing, female respondents tend to do this role compared to male respondents. It can be deduced that women hold local plant knowledge as a result of their daily work, hence, they felt responsible for the conservation and management of herbal or useful plants. Male respondents were active in transmitting their ethnobotanical knowledge to their family members or relatives. One possible reason was that they have extra time to do it especially the senior citizens. Unlike female respondents, they were facing multiple burden, hence, less time for ethnobotanical knowledge transmission.

Table 2. Gender Roles in Traditional Herbal Healing

\begin{tabular}{|c|c|c|c|c|c|c|}
\hline Gender Roles in Traditional Herbal Healing & \multicolumn{3}{|c|}{ Female } & \multicolumn{3}{c|}{ Male } \\
\hline & Self & Others & No & Self & Others & No \\
\hline Plant Gatherer & 6 & 2 & & 7 & 4 & \\
\hline Storer of plant parts & 6 & 2 & & 7 & 4 & \\
\hline $\begin{array}{c}\text { Washer of plant parts ( pre-treatment) } \\
\text { 2Disposer of left over plant parts (post } \\
\text { treatment) }\end{array}$ & 6 & 2 & & 10 & 1 & \\
\hline $\begin{array}{l}\text { Propagator } \\
\text { Plant Conservation }\end{array}$ & & 7 & 4 & \\
\hline
\end{tabular}




\begin{tabular}{|c|l|l|l|l|l|l|}
\hline Protector of wildlings & & & & 1 & & 2 \\
\hline Teller or reminder of plant conservation & 2 & & & & 1 & 2 \\
\hline $\begin{array}{c}\text { Transmitter of traditional ethnobotanical } \\
\text { knowledge }\end{array}$ & 1 & & 7 & 5 & & 6 \\
\hline
\end{tabular}

\section{Sanitation Practices of Traditional Herbal Healers}

\section{Pretreatment}

Four out of eight female respondents washed plant parts with water as their sanitation practice before treatment. Two used alcohol in disinfecting their hands before treatment while the rest no sanitation pre-treatment practice.

Four of the eleven male respondents washed plant parts with water as their sanitation practice while one male respondent washed hands only. The remaining two male respondents showed no sanitation practice before treatment.

Majority of female and male respondents were observant of their pre-treatment sanitation practice particularly on washing plant parts with water. However, washing of plant parts does not guarantee that patient is free from infection.

\section{Treatment}

In observance of health treatment procedure, two out of eight female respondents used alcohol and warm water in applying affected human part, and use of washed or clean plant parts during treatment. Two female respondents use washed or clean plant parts during treatment. The rest of female (4) respondents had no sanitation practice during treatment.

Five out of eleven male respondents used washed or clean plant parts as part of their sanitation treatment. Two male respondents both used alcohol and warm water to apply onto affected human part, and used washed or clean plant parts as sanitation practice during treatment. Two male respondents used alcohol and warm water and apply onto affected human part. The other two male respondents had no sanitation practice during treatment.

Half of the female respondents observed used alcohol and warm water in applying affected human part and washing or cleaning plant parts during treatment as their sanitation practice. Majority of male respondents observed washing or cleaning plant parts as their sanitation practice during treatment. Few used alcohol and warm water in applying affected human part. It can be deduced that male respondents were more conscious on treatment sanitation.

\section{Post of After Treatment}

Two out of eight female respondents disposed waste materials (from human and plants) onto a pit. Two female respondents disposed waste materials onto garbage 
bin for truck collection. The four female respondents had no sanitation practice after treatment.

Seven out of eleven male respondents disposed waste materials (from human and plants) onto a pit. One male respondent observed sanitation practice by waste burning while one let his patient bring the waste materials used in healing. Two of the male respondents had no sanitation practice after treatment.

Half of female respondents were conscious of their waste disposal either onto pit or garbage bin. Moreover, male respondents were more conscious of their waste disposal after treatment compared to female respondents.

Few studies have been conducted on the sanitation practice by the traditional herbal healers in the Philippines. Though herbal healing were being promoted by and among the community people, its sanitation side is being neglected. The practice of sanitation before, during and after treatment play a big role in the outcome of healing and health of the patient. The main objective of sanitation practice is to protect and promote human health by providing a clean environment and breaking the cycle of disease.

The Medical Evidence, online book. (1999) claimed that the sanitation practice saved countless lives of Israelites by protecting them against infection caused by unseen germs. The medical instructions given by Moses to the Israelites some 3500 years ago were not only far superior to the practices of contemporary cultures, they also exceeded medical standards practiced as recently as 100 years ago. The Israelites were instructed to wash themselves and their clothes in running water if they had a bodily discharge, if they came in contact with another person's discharge, or if they had touched a dead human or animal carcass. They were also instructed to wash any uncovered vessels that were in the vicinity of a dead body, and if a dead carcass touched a vessel it was to be destroyed. Items recovered during war were also to be purified through either fire or running water. In addition, the Israelites were instructed to bury their human waste outside of camp, and to burn the waste of their animals.

Sambal-Bolinao particularly women traditional herbal healers were not really conscious of sanitation practice before, during and after treatment. They presumed and felt not to wash hands before and during treatment because they usually stayed at home. Men, on the other hand, usually coming from work outside home, tended to wash hands before and during treatment.

\section{Conclusion}

The Sambal-Bolinao that were Roman Catholic believers appreciated the practice of traditional herbal healing. They extended their roles as plant gatherer, keeper of the plant parts gathered, washer of the plant parts prior to treatment, manager of the plant parts wastes and as plant conservationist either through plant propagation and personal campaign on plant conservation. However, majority of them especially 
women traditional herbal healers did not transmit their ethnobotanical knowledge to their children and other relatives for their multiple burden case and perceived economic difficulty for their children or family members. Men traditional herbal healers were the ones transmitting their ethnobotanical knowledge to their family members.

The nature of work of men which was outside home made them conscious to observe sanitation practice by washing the plant parts with hands and by disinfecting the hands with alcohol or warm water. Women traditional herbal healers which usually stay at home presumed that their hands were already clean and no need of sanitation practice.

\section{Recommendations}

Further validation or study on transmission of ethnobotanical knowledge to the family members of the traditional herbal healers should be conducted. Support in perpetuating the ethnobotanical knowledge particularly from local government and other government agencies should be initiated.

\section{References}

[1] Debela Hunde, Chemeda Abedeta, Techale Birhan and Manju Sharma, 2015. Gendered Division of Labor in Medicinal Plant Cultivation and Management in South West Ethiopia: Implication for Conservation. Trends in Applied Sciences Research, 10:

[2] Fojas, Felix. 2012. The Supernatural Beliefs of Pre-Spanish Filipinos. Just Another Word Press.com. Retrieved from https://felixfojas.wordpress.com/ 2012/10/13/the-supernatural-beliefs-of-pre-spanish-filipinos-by-felixfojas/ on May 7, 2017

[3] Howard, Patricia. 2001. Women in the Plant World: The Significance of Women and Gender Bias for Biodiversity Conservation. A briefing produced for IUCN. Retrieved from https://portals.iucn.org/library/sites/library/files/documents/Rep-2001028.pdf on May 8, 2017 on May 11, 2017.

[4] Medical Evidence. Evidences of the Bible. Online Book. Retrieved from https://bibleevidences.com/medical-evidence/ 77-87..1999.

[5] Saldua, Adrianne Dianne Isabelle R. 2012. The Role of Women from Hispanic to Spanish Era. UP Open University History 1. Retrieved from https://tonkshistory.wordpress.com/2012/02/22/the-role-of-womenfrom-pre-hispanicto-spanish-era/ on May 7, 2017 